\title{
Repair of glulam beams using GFRP rods
}

\author{
G. M. Raftery \& A. M. Harte \\ Department of Civil Engineering, National University of Ireland, Ireland
}

\begin{abstract}
Timber is one of the oldest building materials and is very attractive because it is a renewable resource, recyclable and relatively inexpensive. However, as the service requirements that are imposed on structural members change, mechanical upgrade or repair becomes of increasing importance. This paper describes an experimental test programme which investigates the use of glass fibre reinforced polymer rods (GFRP) for the retrofit of low-grade glue-laminated timber beams, which were tested in bending initially in the unreinforced state for both stiffness and ultimate moment capacity. The test results demonstrated that by correctly carrying out the retrofitting procedure in timber beams that were severely damaged, mechanical strength and flexural stiffness of the original beams could be regained and in addition significant ductility was introduced.
\end{abstract}

Keywords: timber, glulam, repair, rehabilitation, fibre reinforced polymers, experimental testing, strength, stiffness.

\section{Introduction}

\subsection{Timber and fibre reinforced polymers}

Timber is one of the oldest construction materials and possesses many advantages: it is a natural renewable resource with a secure supply, recyclable, commercially attractive, cost competitive and has desirable aesthetic characteristics. It has an excellent strength to weight ratio, is resistant to many of the chemicals destructive to steel and concrete and is a natural insulator.

However, timber also has disadvantages as a structural material. Biological deterioration can occur when exposed to harsh environments over time or through bacteria, fungi, insect or marine borers [1]. Material degradation from decay in timber structural elements can result in a reduction of cross-section size which results in mechanical damage and consequently can inhibit the service 
performance of the structure as a whole. Furthermore, deep checking and splitting resulting from fluctuating environmental conditions may occur in timber structural elements which weaken the members significantly. Often, if degradation is severe, structural deficiencies may require repair.

In recent years, designers in the construction industry have become more aware of the advantages fibre reinforced polymers (FRPs) offer. These advantages include their high strength to weight ratio, high stiffness, ease of handling and good resistance to corrosion. The mechanical properties in the composite are primarily provided by means of glass, aramid or carbon fibres or a mixture. Glass fibres composites are associated with lower strength and stiffness than aramid and carbon fibre composites but are of considerably lower cost.

\subsection{Adhesively bonded-in reinforcement}

Fibre reinforced polymer materials can be easily pultruded in various profiles, including bars, rods and plates. Retrofitting using FRP plates bonded to the soffit of a beam is an option. However, the use of bars or rods adhesively bonded into routed out grooves in the soffit of the member has the advantage of being invisible which maintains the aesthetic characteristics of the timber. Furthermore, repaired beams using bonded-in rods possess better fire-resistance as the FRP is not exposed.

Adhesive bonding is an economical method which transfers the stresses between the reinforcement and the timber uniformly and avoids the stress concentrations incurred with mechanical fastening [2]. Custódio et al. [3] undertook a comprehensive review of factors that influence the durability of structurally bonded timber joints. Raftery et al. [4, 5] concluded from experimental testing that not only did the quality of the bond depend on the adhesive under examination but it also depended on the FRP type that was being bonded.

\subsection{Rehabilitation of timber structural members}

The use of FRP materials in the rehabilitation of structural members was discussed in detail by Hollaway and Teng [6]. Guidance regarding surveying for repair and general technical advice for undertaking rehabilitation work in timber structures is well documented in the literature [7, 8]. A number of studies have examined the use of both steel and fibre reinforced polymers in the rehabilitation of structural timber members. Experimental testing demonstrated that the use of epoxy and bonded in reinforcement is a successful strengthening technique for the deterioration of wooden beam ends [9].

\subsection{Objective}

The objective of the present study was to examine the use of a cost effective GFRP material in the flexural rehabilitation of fractured low-grade gluelaminated structural members. Glue-laminated beams were initially manufactured and tested to failure. These beams were then repaired using two 
different reinforcement configurations comprising adhesively-bonded rods in grooves in the soffit of the beams. The mechanical performance of the repaired beams is compared directly with that of the original beams.

\section{Experimentation}

\subsection{Fabrication of beams}

Glue-laminated beams, 3610m in length, $96 \mathrm{~mm}$ in width, $190 \mathrm{~mm}$ in depth, comprising five laminations of $38 \mathrm{~mm}$ thickness were fabricated using Grade C16, Irish grown Sitka spruce which was conditioned in a controlled environment of $65 \pm 5 \%$ relative humidity and $20 \pm 2^{\circ} \mathrm{C}$ temperature. The beams were made such that the best quality laminations were used in tension (T1) at the bottom of each beam. The next best set of laminations was used in the critical compressive zone at the top of the beams (C1). Subsequently, the secondary tension laminations (T2) were allocated followed by the secondary compressive laminations $(\mathrm{C} 2)$. The remaining laminations which were considered the weakest based on the results from the grading process were placed in the core of the beam. The test programme described in this paper involved ten beams. For six of the ten beams, an additional $25 \mathrm{~mm}$ bottom "sacrificial" lamination was bonded to the tension face of the beams as described in Raftery and Harte [10].

\subsection{Fibre reinforced polymer}

The GFRP rods used for the repair work were Aslan 100. Both $6 \mathrm{~mm}$ and $12 \mathrm{~mm}$ diameter rods were used in the experimental testing. This FRP material is corrosive resistant, non-conductive and weighs approximately one fourth that of steel reinforcing rods. The rods have a modulus of elasticity of $40.8 \mathrm{GPa}$, tensile strength of $620 \mathrm{MPa}$ and bending strength of $11.6 \mathrm{MPa}$. This FRP material is manufactured from continuously drawn E-glass roving saturated with vinyl ester resin. The surface of the rods are purposely deformed and are characterised by its helical wrapped nature which possesses a sand coating to enhance bonding using epoxy adhesives.

\subsection{Adhesives}

The adhesives used for the bonds between the timber laminations and at the FRP-wood interface were selected based on previous studies by Raftery et al. [4, $5,11]$. From the results obtained, a phenol resorcinol formaldehyde (PRF) was selected for the wood-wood laminations and the epoxy adhesive, Sikadur 31 Normal, a well recognised civil engineering two component thixotropic adhesive was considered appropriate for the bond between the GFRP rods and the spruce.

\subsection{Initial testing of beams}

All beams were tested in four-point bending over a span of 18 times the beam depth in accordance with EN408 [12] using a Dartec 500kN testing machine. Loading rates of $0.057 \mathrm{~mm} / \mathrm{sec}$ and $0.0645 \mathrm{~mm} / \mathrm{sec}$ for the $190 \mathrm{~mm}$ deep and $215 \mathrm{~mm}$ deep beams, respectively, were used in the determination of the global 
and local stiffness. Global stiffness is determined from centre span deflection in relation to the supports while local stiffness is a measurement taken in the zone of maximum moment between the two loading heads. Two linear variable displacement transducers (LVDTs) were used to measure the deflection of the beam. Lateral supports were positioned approximately $300 \mathrm{~mm}$ outside of the loading heads and frictional effects were reduced to a minimum by the use of polytetrafluoroethylene (PTFE) strips sliding over each other. Strength testing of the beams involved loading at a constant displacement rate such that failure occurred in $300 \pm 120$ seconds. The failed beams were then straightened using the Dartec $500 \mathrm{kN}$ before retrofitting with FRP rods.

\subsection{Beam repair methodology}

Of the four $190 \mathrm{~mm}$ deep beams tested, two were reinforced using $12 \mathrm{~mm}$ diameter GFRP rods in two grooves $(1.39 \%$ reinforcement) and two were reinforced using two $6 \mathrm{~mm}$ diameter GFRP rods in three grooves $(1.04 \%$ reinforcement). The same test programme was followed for the $215 \mathrm{~mm}$ deep beams except three beam samples were tested for each configuration. For these beams, the $12 \mathrm{~mm}$ diameter rods employed $1.04 \%$ for the beams reinforced with the $12 \mathrm{~mm}$ diameter rods and $0.92 \%$ for the beams reinforced with the $6 \mathrm{~mm}$ diameter rods. The repair methodology involved pairing beams of similar depth and stiffness together and assessing the severity of the fractures after testing in the unreinforced state. The beam adjudged to be more severely fractured in each pair was repaired using the greater reinforcement percentage which involved the $12 \mathrm{~mm}$ diameter rods. The two reinforcement arrangements with corresponding grooves sizes for each beam type repaired for the $190 \mathrm{~mm}$ deep beams are shown in Figure 1. The reinforcement arrangements for the $215 \mathrm{~mm}$ deep beams were similar except the grooves were routed into the $25 \mathrm{~mm}$ bottom additional lamination.

Directly after the routing procedure was complete, the grooves were vacuum cleaned to remove loose particles which could inhibit the performance of the bond. The GFRP rods were wiped clean with methylated spirits thirty minutes prior to adhesive bonding. A base layer of the epoxy adhesive, Sikadur 31, was initially inserted into the groove. The rods were then centrally placed in the groove so that the stresses incurred during retesting are uniformly dissipated by the adhesive prior to failure of the beam. The remainder of the void around the reinforcing rods was subsequently filled with the epoxy adhesive. The repaired beams were transferred to an environment of $65 \pm 5 \%$ relative humidity and temperature of $20 \pm 2^{\circ} \mathrm{C}$ for twenty days prior to testing following the procedure described in Section 2.4 above.

\section{Results}

\subsection{Load deflection behaviour}

The load deflection behaviour of the beams as originally tested in the unreinforced condition and as repaired is seen in Figures 2 to 5. 

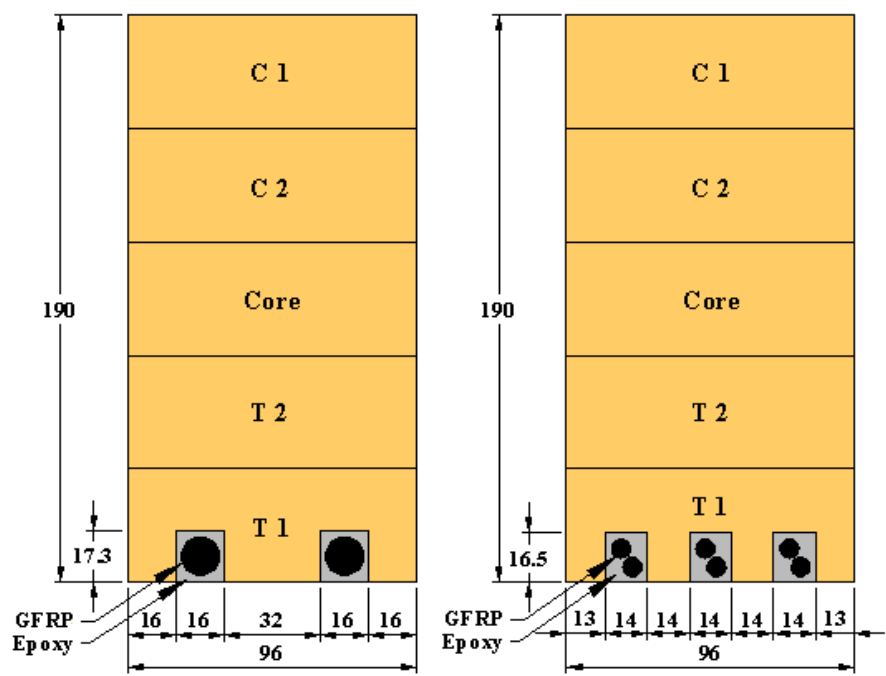

Figure 1: Reinforcement arrangement for repaired 190mm deep beams.

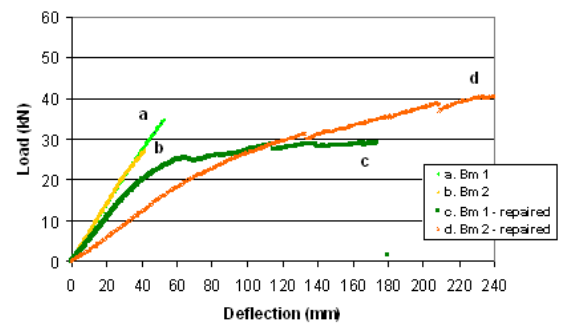

Figure 2: $190 \mathrm{~mm}$ deep beams $12 \mathrm{~mm}$ GFRP rods $(1.39 \%)$.

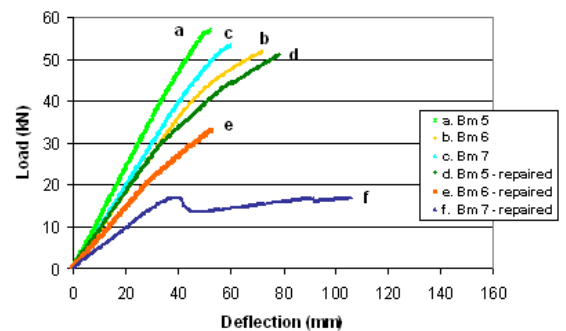

Figure 4: $215 \mathrm{~mm}$ deep beams$12 \mathrm{~mm} \quad$ GFRP rods $(1.04 \%)$.

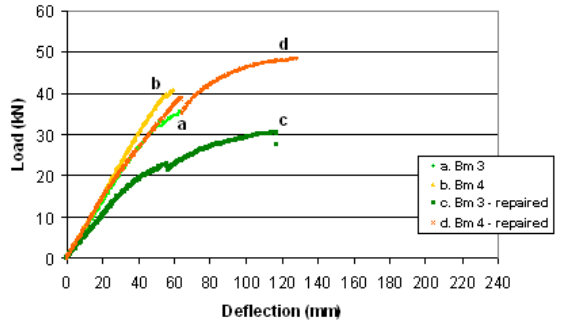

Figure 3: $190 \mathrm{~mm}$ deep beams $6 \mathrm{~mm}$ GFRP rods (1.23\%).

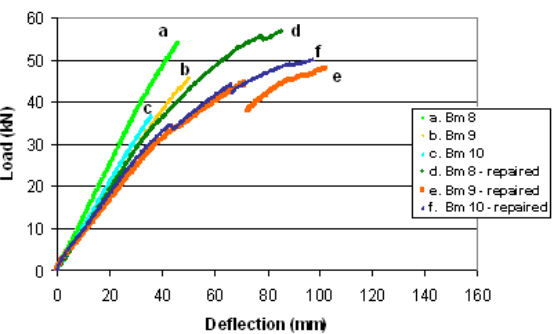

Figure 5: $215 \mathrm{~mm}$ deep beams $6 \mathrm{~mm}$ GFRP rods $(0.92 \%)$. 
In general, the beams tested in the unreinforced state failed in brittle tension and exhibited little plastic behaviour in comparison to the repaired beams. Furthermore, it is seen that when the beams are retrofitted with a higher reinforcement percentage, there exists considerably greater plastic behaviour as can be seen for the $190 \mathrm{~mm}$ deep beams.

\subsection{Failure modes of beams}

\subsubsection{Beams 1-2: 190mm deep beams, $12 \mathrm{~mm}$ reinforcing rods}

Beam 1 was considered to be the most severely fractured of the $190 \mathrm{~mm}$ deep beams and exhibited a combined bending and shear failure with fractures over the width of the beam. Beam 2 exhibited a shear and tension failure in the unreinforced state. Repaired Beam 1 ruptured at a knot in the bottom tension lamination after significant plastic deformation. Repaired Beam 2 exhibited considerable plastic compression behaviour at a knot in the top lamination.

\subsubsection{Beams 3-4: 190mm deep beams, $6 \mathrm{~mm}$ reinforcing rods}

In the unreinforced state, Beam 3 failed in tension at a weakness associated with a knot in the bottom lamination and the fracture propagated through the tension laminations prior to a shear crack being caused between the core and T1 lamination (Figure 6). The repaired beam displayed significant compression wrinkling at a knot in the top lamination prior to failure when the previous fracture reopened (Figure 7). Fracture in the clear wood between the routed out grooves in which the bonded in reinforcing rods were positioned was also noted thus demonstrating the significant stresses carried by the GFRP rods. Beam 4 failed in a similar manner to Beam 3 in the unreinforced state. The repaired beam demonstrated considerable plasticity prior to fracture at a knot above the bottom lamination.

\subsubsection{Beams 5-7: $215 \mathrm{~mm}$ deep beams, $12 \mathrm{~mm}$ reinforcing rods}

The tensile stresses experienced at a knot in the sacrificial lamination were the primary cause of failure for Beam 5. A fracture travelled up through the beam as

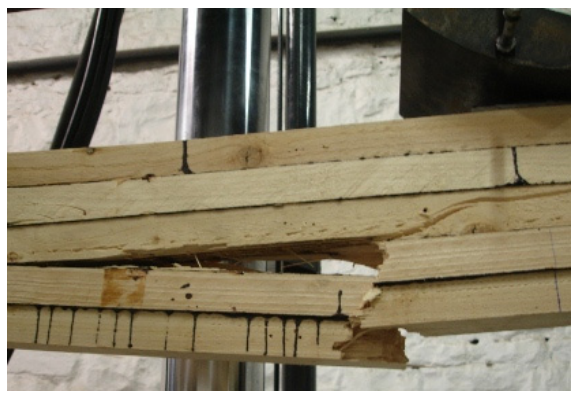

Figure 6: $\mathrm{Bm} 3-$ unreinforced failure.

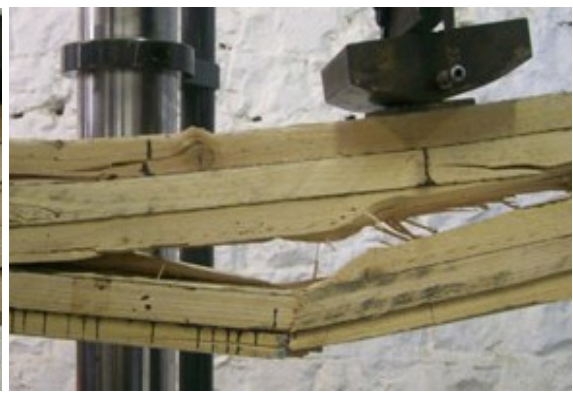

Figure 7: $\quad \mathrm{Bm} 3-$ repaired failure. 


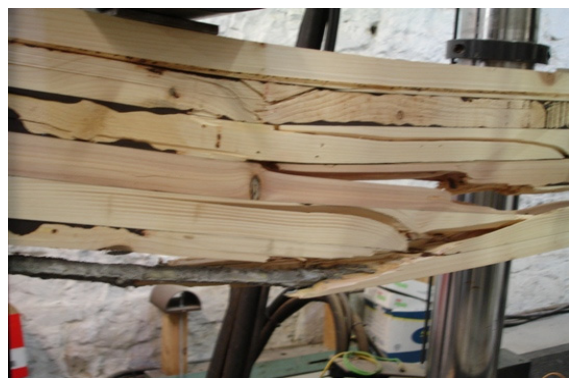

Figure 8:
Bm 7 - repaired failure.

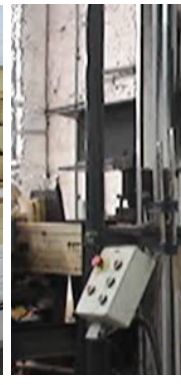

Figure 9:

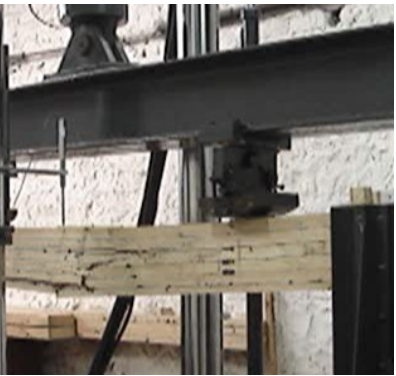

Bm 8 - unreinforced failure.

well as a shear crack occurred between the bottom lamination and the T2 lamination. When repair and retesting of the beam was complete, fracture was initiated from the same location after significant plastic behaviour was exhibited.

Beam 6 exhibited a combined shear and tension failure which initiated in the clear wood of the bottom lamination. This initial fracture propagated to a significant knot located in the T1 lamination and subsequently to a knot in the core lamination in the region of maximum bending moment which was offcentred to the left hand end of the beam. The beam when retested using the $12 \mathrm{~mm}$ reinforced rods failed suddenly in shear in the core lamination where fracture was noted after testing in the unreinforced state and the failure ran the length of the beam. Beam 7 was considered the most severely fractured of the $215 \mathrm{~mm}$ deep beams tested and exhibited a brittle tension fracture at a knot in the unreinforced state. After the re-straightening and routing procedure was complete, the beam continued to exhibit noticeable curvature. The beam, when fitted with the GFRP rods, failed prematurely in the bond line because the groove remained curved and an inadequate adhesive bond line thickness surrounded the $12 \mathrm{~mm}$ FRP rod at the initial fracture location from when the beam failed in its unreinforced state (Figure 8).

\subsubsection{Beams 8-10: $215 \mathrm{~mm}$ deep beams, $6 \mathrm{~mm}$ reinforcing rods}

Beam 8, 9 and 10 all failed in the unreinforced condition in tension at the location of a knot (Figure 9). Upon fracture, cracks were also seen to propagate along the annular ring in shear. The beams exhibited no ductility. Beam 8 , when repaired, displayed compression buckling at a knot in the top lamination prior to fracture of the beam. At ultimate strength of the repaired beams, fracture occurred in the bottom lamination. This fracture progressed along an annular ring in the T1 lamination. The repaired beam 9 exhibited ductile behaviour with visible compressive buckling noted on the top lamination at a knot location. The beam fractured above the reinforcement rods with the fracture path progressing the length of the structural member along an annular ring in the T1 lamination. Although the reinforcement was positioned near the extreme stressed fibres at the bottom the beam, the repaired beam failed above the GFRP rods in a less stressed location which illustrates the effectiveness of the reinforcement. When 
repaired, Beam 10 displayed compression buckling at a knot in the $\mathrm{C} 1$ lamination and continued into the $\mathrm{C} 2$ lamination. The significant bending stresses which were carried by the rod reinforcement were noted by the fracturing of the timber which separated the channels in which the rods were inserted after failure initiated in the bottom lamination.

\subsection{Stiffness}

Both local and global stiffness results are compared for the unreinforced and repaired beams in Table 1. Although, the beams repaired with the $12 \mathrm{~mm}$ diameter rods were more severely fractured in general, it was nevertheless seen that the percentage local stiffness recovered was significantly higher when using a greater reinforcement percentage as provided by the $12 \mathrm{~mm}$ rods $(1.39 \%$ for $190 \mathrm{~mm}$ deep beam, $1.23 \%$ for $215 \mathrm{~mm}$ deep beams) in comparison to repairing less severely fractured beams with the $6 \mathrm{~mm}$ rod arrangement $(1.04 \%$ for $190 \mathrm{~mm}$ deep beam, $0.92 \%$ for $215 \mathrm{~mm}$ deep beams). Furthermore, the percentage global stiffness restored was generally greater than that of the percentage local stiffness restored because failure of the unreinforced beams was always initiated from a weakness in the zone of maximum bending moment and damage usually was localised to this zone.

Although, it is seen that a significant proportion of the stiffness of the original beams was restored, in no case is $100 \%$ or greater of both the local and global stiffness restored. A contributory factor to this behaviour is believed to be the presence of shear cracks that were initiated from the tension failures in a number of the failed beams.

Table 1: $\quad$ Bending stiffness of originally tested and repaired beams.

\begin{tabular}{|c|c|c|c|c|c|c|}
\hline Beam & $\begin{array}{l}\text { Unreinforced } \\
\text { Global El } \\
\left(\mathrm{Nmm}^{2}\right)\end{array}$ & $\begin{array}{l}\text { Repaired } \\
\text { Global El } \\
(\text { Wmm²) }\end{array}$ & $\begin{array}{c}\% \\
\text { Recolvered }\end{array}$ & $\begin{array}{l}\text { Unreinforced } \\
\text { Lacal El } \\
\text { (Nmm²) }\end{array}$ & $\begin{array}{l}\text { Repaired } \\
\text { Local El } \\
\left(\mathrm{Nmm}^{2}\right)\end{array}$ & $\begin{array}{c}\% \\
\text { Recovered }\end{array}$ \\
\hline \multicolumn{7}{|c|}{$190 \mathrm{~mm}$ Deep Beams - $12 \mathrm{~mm}$ diameter rods } \\
\hline 1 & $4.59 E+11$ & $3.57 \mathrm{E}+11$ & 77.64 & $5.20 \mathrm{E}+11$ & $4.50 \mathrm{E}+11$ & 86.53 \\
\hline 2 & $5.49 E+11$ & $5.39 E+11$ & 98.17 & $6.59 \mathrm{E}+11$ & $5.27 \mathrm{E}+11$ & 79.89 \\
\hline \multicolumn{7}{|c|}{$190 \mathrm{~mm}$ Deep Beams - Gmm diameter rods } \\
\hline 3 & $4.85 E+11$ & $3.82 \mathrm{E}+11$ & 78.86 & $5.32 \mathrm{E}+11$ & $3.41 \mathrm{E}+11$ & 64.11 \\
\hline 4 & $4.97 E+11$ & $4.41 \mathrm{E}+11$ & 88.81 & $5.45 \mathrm{E}+11$ & $5.27 \mathrm{E}+11$ & 96.63 \\
\hline \multicolumn{7}{|c|}{$215 \mathrm{~mm}$ Deep Beams - $12 \mathrm{~mm}$ diameter rods } \\
\hline 5 & $8.20 \mathrm{E}+11$ & 6.08E+11 & 74.10 & $8.85 E+11$ & $5.91 \mathrm{E}+11$ & 66.71 \\
\hline 6 & $6.17 E+11$ & $4.86 E+11$ & 78.89 & $6.62 \mathrm{E}+11$ & $7.0 \mathrm{EE}+11$ & 106.88 \\
\hline $7^{*}$ & 6.84E+11 & $4.37 E+11$ & 63.86 & $7.65 \mathrm{E}+11$ & $5.76 \mathrm{E}+11$ & 75.31 \\
\hline \multicolumn{7}{|c|}{$215 \mathrm{~mm}$ Deep Beams - Gmm diameter rods } \\
\hline 8 & 8. $45 E+11$ & $6.54 \mathrm{E}+11$ & 77.40 & $9.57 E+11$ & $5.79 \mathrm{E}+11$ & 60.46 \\
\hline 9 & $6.63 E+11$ & $5.03 \mathrm{E}+11$ & 75.83 & $6.97 \mathrm{E}+11$ & $3.71 \mathrm{E}+11$ & 53.27 \\
\hline 10 & $7.13 E+11$ & $5.80 \mathrm{E}+11$ & 81.32 & $7.67 E+11$ & $4.15 E+11$ & 54.15 \\
\hline
\end{tabular}

* Excessively bad fracture 
Table 2: $\quad$ Ultimate bending moment of originally tested and repaired beams.

\begin{tabular}{|c|c|c|c|}
\hline Beam & $\begin{array}{c}\text { Unreinforced } \\
\text { Ultimate loment } \\
\text { (kNm) }\end{array}$ & $\begin{array}{c}\text { Repaired } \\
\text { Ultimate Moment } \\
\text { (kM) }\end{array}$ & $\begin{array}{c}\% \\
\text { Recowered }\end{array}$ \\
\hline \multicolumn{4}{|c|}{ 190mm Deep Beams - $12 \mathrm{~mm}$ diameter rods } \\
\hline 1 & 20.32 & 17.41 & 85.68 \\
\hline 2 & 23.28 & 27.61 & 118.64 \\
\hline \multicolumn{4}{|c|}{ 190mm Deep Beams - Gmm diameter rods } \\
\hline 3 & 19.77 & 16.62 & 84.03 \\
\hline 4 & 15.58 & 23.16 & 148.67 \\
\hline \multicolumn{4}{|c|}{$215 \mathrm{~mm}$ Deep Beams - $12 \mathrm{~mm}$ diameter rods } \\
\hline 5 & 30.31 & 27.05 & 89.25 \\
\hline 6 & 27.56 & 17.47 & 63.38 \\
\hline $7^{*}$ & 28.46 & 9.59 & 33.68 \\
\hline \multicolumn{4}{|c|}{$215 \mathrm{~mm}$ Deep Beams - Gmm diameter rods } \\
\hline 8 & 28.73 & 30.11 & 104.92 \\
\hline 9 & 24.33 & 25.56 & 105.06 \\
\hline 10 & 19.57 & 26.65 & 136.22 \\
\hline
\end{tabular}

\subsection{Ultimate bending moment capacity}

The strength testing results as obtained for the unreinforced and the repaired beams in relation to ultimate bending moment capacity can be seen in Table 2.

Both configurations of the GFRP reinforcement examined for the $190 \mathrm{~mm}$ deep beams showed that the moment capacity of the unreinforced beams could be recovered if not improved with the repair procedure undertaken. For the $215 \mathrm{~mm}$ deep beams repaired using the $12 \mathrm{~mm}$ reinforcement rods, the effectiveness of the repair work was shown when the repaired Beam 5 recovered $89 \%$ of the ultimate moment of the unreinforced beams. The moment capacity recovered for Beam 6 was $63.38 \%$ which was low but fracture occurred above the reinforcement layer which illustrates both the effectiveness of the reinforcement as well as how severe the fracture in the beam was. Beam 7 had an excessively bad fracture and prior to the testing of the repaired beam, it was believed that the moment capacity recovered would be poor. For all of the $215 \mathrm{~mm}$ deep beams reinforced with the $6 \mathrm{~mm}$ rods, the ultimate moment capacity of the beams, when repaired, exceeded that when tested in the unreinforced condition.

\section{Conclusions}

It is shown from experimental testing that using GFRP rods to repair low grade glue-laminated spruce beams in flexure can be an effective and feasible technique. It is considered that this technology if correctly applied is favourable 
for the on-site repair of partially deteriorated timber structures and is also considered suitable for upgrade of existing structures.

It should be noted that all the beams which were repaired in this test programme were severely fractured after strength testing in the unreinforced condition. In a number of the tests involving the repaired beams, fracture was seen to occur in lower stressed zones towards the neutral axis of the section where tensile fracture perpendicular to grain occurred in the original beams and propagated in a crack along the annular ring. This behaviour indicated the severity of the damage to the original beams as well as the effectiveness of the reinforcement.

It was seen that the unreinforced glue-laminated beams failed in brittle tension while a more ductile compressive flexural behaviour was exhibited by the repaired beams. In no circumstance was failure in the reinforcement rods found during the testing programme and in general significant stiffness and moment capacity was recovered. Further testing is recommended to obtain a greater understanding of the effectiveness of the reinforcement. It is also proposed to employ FRP material incorporating aramid or carbon fibres to further improve the stiffness of the section and also to examine the use of FRP materials in the shear strengthening of timber structural members.

With the exception of Beam 7 which was excessively damaged prior to retrofit, a bond of high quality was formed by the epoxy adhesive and no premature failure prior to fracturing of the repaired beams was experienced in the test programme.

\section{Acknowledgements}

The authors would like to express their sincere thanks to Banagher Concrete Ltd. and Hughes Brothers, U.S.A for the donation of the GFRP reinforcement rods and to the National University of Ireland, Galway for financial support. The assistance of Mr. Richard Dodd and Mr. Seán Ó hIarnáin is appreciated.

\section{References}

[1] Smith, I., Landis, E. \& Gong, M., Fracture and fatigue of wood, John Wiley \& Sons, 2003.

[2] Mays, G.C. \& Hutchinson, A.R., Adhesives in Civil Engineering, Cambridge University Press, The Pitt Building, Trumpington Street, Cambridge, 1992.

[3] Custodio, J., Broughton, J. \& Cruz, H., A review of factors influencing the durability of structural bonded timber joints, International Journal of Adhesion and Adhesives, 29 (2), pp. 173-185, 2009.

[4] Raftery, G.M., Harte, A.M. \& Rodd, P.D., Bond quality at the FRP wood interface using conventional wood laminating adhesives, International Journal of Adhesion and Adhesives, 29 (2), pp.101-110, 2009. 
[5] Raftery, G.M., Harte, A.M. \& Rodd, P.D., Bonding of FRP materials to wood using thin epoxy gluelines, International Journal of Adhesion and Adhesives, 29 (5), pp. 580-588, 2009.

[6] Hollaway, L.C., \& Teng, J.G., Strengthening and Rehabilitation of Civil Infrastructures Using Fibre-reinforced Polymer (FRP) Composites, Taylor \& Francis Group, 2008.

[7] Yeomans, D.J., The Repair of Historic Timber Structures, Thomas Telford Ltd, 2003.

[8] Ross, P., Appraisal and Repair of Timber Structures, American Society of Civil Engineers (Thomas Telford Ltd.), 2002.

[9] Van Gemert, D. \& Vanden Bosch, M., Structural restoration of wooden beams by means of epoxy resin, Materials and Structures, 20, pp. 165-170, 1987.

[10] Raftery, G.M. \& Harte, A.M., Experimental testing of FRP plate reinforced glulam, Proc. of Advanced Composites in Construction, Edinburgh, 2009.

[11] Raftery, G.M., Harte, A.M. \& Rodd, P.D., Qualification of wood adhesives for structural softwood glulam with large juvenile wood content, Journal of the Institute of Wood Science, 18 (1), pp. 24-34, 2008.

[12] EN 408, Timber structures. Structural timber and glued laminated timber. Determination of some physical and mechanical properties, 1995. 